\title{
Modelling of the Behaviour of a Welded Joint subjected to Reverse Bending Moment at High
}

\section{Temperature}

\author{
Alan R. S. Ponter and Haofeng Chen \\ Department of Engineering, University of Leicester, Leicester, LE1 7RH, UK \\ e-mail: asp@le.ac.uk ,Tel UK+1162522549, Fax UK+1162522525
}

\begin{abstract}
.
Background. The paper is concerned with the modelling of the behaviour of welds when subjected to severe thermal and mechanical loads where the maximum temperature during dwell periods lies in the creep range. The methodology of the Life Assessment Method R5 is applied where the detailed calculations are carried out using the Linear Matching Method, with the objective of generating an analytic model.
\end{abstract}

Method of Approach. The Linear Matching Method (LMM) has been developed to allow accurate predictions using the methodology of R5, the UK Life Assessment Method. The method is here applied to a set of weld endurance tests, where reverse bending is interrupted by creep dwell periods. The weld and parent material are both Type $316 \mathrm{~L}(\mathrm{~N})$ material and data was available for fatigue tests and tests with $1 \mathrm{hr}$ and $5 \mathrm{hr}$ dwell periods to failure. The elastic, plastic and creep behaviour of the weld geometry is predicted using the LMM using the best available understanding of the properties of the weld and parent material. The numerical results are translated into a semi-analytic model. Using the R5 standard creep/fatigue model, the predicted life of the experimental welds specimens are compared with experimental data.

Results. The analysis shows that the most severe conditions occur at the weld/parent material interface, with fatigue damage predominantly concentrated in the parent material, whereas the creep damage occurs predominantly in the weld material. Hence creep and fatigue damage proceed relatively independently. The predictions of the model are good, except that the reduction in fatigue life due to the presence of the weld is underestimated. This is attributed to the lack of separate fatigue date for the weld and parent material and the lack of information concerning the heat affected zone. With an adjustment of a single factor in model, the predictions are very good.

Conclusion. The analysis in this paper demonstrates that the primary properties of weld structures may be understood through a number of structural parameters, defined by cyclic analysis using the Linear Matching method and through the choice of appropriate material data. The physical assumptions adopted conform to those of the R5 Life Assessment Procedure. The resulting semi-analytic model provides a more secure method for extrapolation of experimental data than previously available.

\section{Introduction}

In the design and life assessment of structures of austenitic steels that operate at high temperatures, the performance of welds provides a particular difficulty. Their performance under variable load and temperature is complex and variable. Traditionally, 
design codes have taken welded joints into account by assigning increased factors of safety on allowable loads and temperatures compared with the factors that apply when welds are absent. These factors are determined from experimental data and experience in practice. When high temperature failures occur, there is a high probability that the failure will initiate at a weld. The practice of increased factors of safety discourages designers from allowing a weld to become the primary carrier of load, but in many circumstances the need to ensure welds are subjected to sufficiently low loads can dominate the overall design.

There is an urgent need to understand the various factors that effect weld strength. In this paper we are concerned with the effect of variable load at high temperature. The problem under consideration is shown schematically in Figs. 1(a) and 1(b). A continuous plate is divided, at its centre, into two parts each of which is welded to the surface of a third plate. Hence the weld joint consists of two symmetrically placed identical welds. The simplest description of a typical weld subdivides the material into three regions, the parent material, assumed uniform away from the weld, the weld material and a thin layer, the heat effected zone (HAZ), between the weld and parent material. Each of these regions would be expected to have separate material properties. Differences in elastic properties induce local stress raisers at the interfaces; differences in plastic deformation properties combine with the elastic properties to produce local plastic strain concentrations. During dwell periods, differences in the creep deformation properties as well as elastic properties will influence the location and magnitude of creep strain produced during stress relaxation. The ultimate failure of the component then depends upon the fatigue and creep damage properties which, again, will vary between the three component materials.

In modelling this situation the objective must be to gain an understanding of the relationship between possible variations in the material within the weld and the lifetime of the component for a practical range of load variation and dwell time. There are two difficulties in successfully completely such an analysis; the material behaviour may not be well understood and the analysis required is very demanding. In the following we concentrate upon a geometry and loading history for which experimental data exists, Bretherton et al [1,2], making use of a range of data for this particular material, Type 316L(N) austenitic stainless steel. For analysis we use methods based upon the Linear Matching Method that have already been developed for creep/fatigue interaction applications in the UK life assessment method R5, Chen and Ponter [3-8]. This allows the development of a model that may be directly compared with tests conducted on welds and, at the same time, provides insight into the sensitivity of the life upon material and loading parameters.

The assumptions in the analysis are very simple. Plastic strains are modelled by a Ramberg-Osgood expression. Creep is modelled by a time hardening law. Failure assumes a linear summation of fatigue damage and creep damage. Creep damage is modelled as strain exhaustion. There is no interaction between creep strain and plastic strain. Our main objective is to obtain, for this particular weld geometry, a semi-analytic model of failure that may be developed for other geometries, material data and failure laws. 


\section{The Cruciform Weld Specimen}

The geometry of the weld specimen is shown in Figs, (1a) and (1b), where a plate of width $200 \mathrm{~mm}$ and length of $1.8 \mathrm{~m}$ is divide and welded to plate of length $100 \mathrm{~mm}$, as shown in Fig. (1b), forming a cruciform specimen. The arms of the specimen are subjected to a bending moment history, Fig. (1c), consisting of a rapid reversal of bending moment of magnitude $\Delta M=2 \bar{M}$ separated by dwell periods of length $\Delta t$ when the moment is maintained constant at $M=\bar{M}=\Delta M / 2$. The geometry of the welds is shown in Fig. (1b). A number of experiments had been carried out on such specimens made of $316 \mathrm{~N}(\mathrm{~L})$ austenitic stainless steel at a constant temperature of $550^{\circ} \mathrm{C}$ by Bretherton et al [1,2] and for various values of $\bar{M}$ and $\Delta t$, details of which are described below. The analysis described below was conducted to characterise the steady state response of these specimens and the initiation of failure; the material data used is discussed in the next section.

\section{Material Description}

The total strain was assumed to consist of the sum of elastic, plastic and creep components,

$$
\varepsilon_{i j}=\varepsilon_{i j}^{e}+\varepsilon_{i j}^{p}+\varepsilon_{i j}^{c}
$$

where the elastic component $\varepsilon_{i j}^{e}$ was characterised by Young's modulus E and Poisson's ratio $v$. For the plastic component, two separate descriptions were used. For the evaluation of standard structural strength parameters such as limit, shakedown and ratchet limits, a perfectly plastic model was used with a von Mises yield condition and yield stress $\sigma_{y}$. For the evaluation of the amplitude of plastic strain, a Ramberg-Osgood expression was used between the plastic strain amplitude $\Delta \varepsilon_{i j}^{p}$ and stress amplitude $\Delta \sigma_{i j}$,

$$
\Delta \varepsilon_{i j}^{p}=\frac{3 \Delta \sigma}{2 \Delta \varepsilon^{p}} \Delta \sigma_{i j}, \quad \frac{\Delta \varepsilon^{p}}{2}=\left(\frac{\Delta \sigma}{2 A}\right)^{\frac{1}{\beta}}
$$

where $\Delta \sigma=\bar{\sigma}\left(\Delta \sigma_{i j}\right)$ and $\Delta \varepsilon^{p}=\bar{\varepsilon}\left(\Delta \varepsilon_{i j}^{p}\right)$ and $(\bar{\sigma}, \bar{\varepsilon})$ refer to von Mises effective values. The two plasticity models are related by defining the yield stress as half the stress range that results from a strain range of $0.2 \%$ in the steady state;

$$
\sigma_{y}=\frac{\Delta \sigma_{0.2 \%}}{2}=A\left(\frac{\Delta \varepsilon_{p}}{2}\right)^{\beta}, \Delta \varepsilon_{p}=0.2 \%
$$

Table 1 lists the material parameters for $316 \mathrm{~N}(\mathrm{~L})$ austenitic stainless steel at $550^{\circ} \mathrm{C}$ for the parent, weld and heat affected zone. The Ramberg-Osgood parameters are measured from tests taken to failure and three sets of values are listed here, from the first and $100^{\text {th }}$ cycle and also from the saturated steady state. 
For the evaluation of the creep properties, separate relations were available for primary and secondary creep at $550^{\circ} \mathrm{C}$. The primary uniaxial creep was give by the Norton-Bailey equation,

$$
\varepsilon_{c r}=2.9618 \times 10^{-15} t^{0.42131} \sigma^{4.18}
$$

where time $t$ is in hours and stress in MPa. Hence the primary creep strain rate may be calculated by:

$$
\dot{\varepsilon}_{c r}=1.2478 \times 10^{-15} t^{-0.57869} \sigma^{4.18}
$$

The time at the end of primary creep was determined by $t=4.4926 \times 10^{19} \sigma^{-6.9467}$. For secondary creep, the creep rate is

$$
\dot{\varepsilon}_{c r}=5.29 \times 10^{-28} \sigma^{8.2}
$$

Based upon the cyclic stress strain data, for both parent and weld materials, semi-total stress range is less than 400MPa when the semi-total strain range is less than $1 \%$. In the experimental results to be discussed below, the maximum outer fibre total strain range is $1 \%$. Hence, the maximum cyclic stress at the stress concentration during the hold period is assumed to be no more than 400MPa, the minimum time at the end of primary creep $t=4.4926 \times 10^{19} \times 400^{-6.9467}=38$ hours . As the hold periods are 1 or 5 hours only primary creep need to be considered for comparison with the test data.

\section{4. $\quad$ Elastic Analysis}

The finite element mesh for a two dimensional symmetric model of the cruciform specimen is shown in Fig. (2a) for the weld and parent materials. The mesh comprises 8-noded generalised plane strain quadrilateral elements. We find that the inclusion of the heat affected zone has a negligible effect on the solutions reported here.

\section{Shakedown and Ratchet Limit Analysis}

The limit load, shakedown limit and ratchet limit was evaluated for a perfectly plasticity and a von Mises yield condition. The history of bending moment consisted of a variation between $M=M_{A}+\bar{M}$ and $M=M_{A}-\bar{M}$, i.e. a variation of $\Delta M=2 \bar{M}$ and a constant addition moment $M_{A}$. The analysis was carried out using the Linear Matching Method, Chen and Ponter [3,4], and the resultant boundaries are shown in the interaction diagram, Fig. (2b), in $\left(M_{A} / M_{L}, \Delta M / \Delta M_{s h}\right)$ space where $M_{L}$ and $\Delta M_{s h}$ denote the limit moment and shakedown limit respectively,

$$
M_{L}=7.438 \mathrm{kNm}, \Delta M_{s h}=10.056 \mathrm{kNm}=1.352 M_{L}
$$

The diagram is divided into four regions, shakedown (including elastic) S, Reverse plasticity P, and Ratchetting R. Also included is the boundary between the $\mathrm{P}$ and $\mathrm{R}$ regions assuming complete cyclic hardening $(\mathrm{CH})$, Chen and Ponter [4]. For various degrees of cyclic hardening, the boundary would lie between this boundary $(\mathrm{CH})$ and the boundary corresponding to perfect plasticity 
(EPP). The $\Delta M$ values corresponding to the experimental results are shown as crosses and all lie within the reverse plasticity region.

\section{Steady State Cyclic Plasticity}

We first consider the case when creep deformation is ignored and the Ramberg-Osgood equation applies. Again the Linear Matching Method, Chen and Ponter [4], was used where steady state cyclic hardening solutions are generated. For the case $\Delta M=12.466 \mathrm{kNm}=1.24 \Delta M_{s h}$, the variation of $\Delta \varepsilon^{p}=\bar{\varepsilon}\left(\Delta \varepsilon_{i j}^{p}\right)$ along the path $\mathrm{A}$ to $\mathrm{B}$ is shown in Fig, (3a). The maximum plastic strain occurs at the parent/weld interface within the parent material. Within the weld, the plastic strain rapidly decreases and remains negligible within most of the weld material. At the interface, however, there is a significant strain concentration factor. The variation of the maximum von Mises stress along AB is shown in Fig. (3b). In this case the maximum stress occurs at the weld interface within the weld material. This distinction between the position of the maximum strain range (in the parent material) and the maximum stress (in the weld material), is important in understanding the two modes of damage due to fatigue and creep and their interaction.

\section{Creep Relaxation during Dwell Period}

During the dwell period, stress relaxation occurs as creep strains are substituted for elastic strains. The resulting overall deformation can only be understood if the interaction between plastic and creep strains occurs. The analysis of such situations has been discussed by Chen and Ponter [8] and applied to a number of problems, Chen and Ponter [5-8]. Here we adopt the same methodology as used in Chen and Ponter [8]. The numerical solutions for dwell periods of both $1 \mathrm{hr}$ and $5 \mathrm{hrs}$ show that the creep strains have a negligible effect on the plastic strain range. Figure (4) shows that the creep strains are small compared with the plastic strains, Fig.(4a), and the stress drop is small compared with the initial stress, Fig.(4b). The maximum creep strain occurs, as expected, at the position of maximum stress, i.e. at the weld/parent interface, but within the weld material, and not at the position of maximum plastic strain. Hence the primary interaction between elastic/plastic and creep strains occurs through the definition of the maximum stress by the elastic and plastic properties.

An important parameter that governs the interaction between creep and elasticity is the elastic follow-up factor $Z$, defined as

$$
Z=\frac{\bar{E} \Delta \varepsilon_{c}}{\Delta \sigma_{c}}
$$

where $\bar{E}=\frac{3 E}{2(1+v)}$ denotes the effective elastic modulus, $\Delta \sigma_{c}$ is the drop in effective stress and $\Delta \varepsilon_{c}$ is the effective accumulated creep strain during the dwell period as shown in Fig. (4). The extreme $Z=1$ corresponds to relaxation with zero change in total strain and $Z \rightarrow \infty$ corresponds to steady state creep with no stress relaxation. Table (2) shows the values obtained 
at either side of the weld/parent interface. It can be seen that the values are sensitive to location but not to dwell time. The variation with load will be discussed below.

\section{8. $\quad$ Predicted Lifetimes}

On the basis of these deformation based calculations, it is now possible to predict the weld lifetime in terms of the number of cycles to failure and dwell period. Where comparisons with experimental results are concerned, this presents a difficulty as the fatigue behaviour of the weld material was not available. The number of cycles to failure $N_{f}$ for tests with no dwell period for the parent material was expressed in terms of the total strain range $\Delta \varepsilon_{t}$ in $\%$;

$$
\log \left(\Delta \varepsilon_{t}(\%)\right)=m_{1}\left(\log \left(N_{f}\right)\right)^{2}+m_{2} \log \left(N_{f}\right)+m_{3}
$$

where, for the parent material, $m_{1}=0.085943, m_{2}=-0.94691$ and $m_{3}=2.2274$.

The creep endurance $D_{c}$, the proportion of the creep ductility exhausted in each cycle, and $N_{c}$, the number of cycles to failure due to creep alone, are given by

$$
D_{c}=\frac{\Delta \varepsilon^{c}}{\varepsilon_{L}}, \quad N_{c}=\frac{1}{D_{c}}
$$

where, as before, $\Delta \varepsilon^{c}$ is the accumulated creep strain during relaxation and $\varepsilon_{L}$ is the creep ductility. Again, data was not available for the weld material. For the parent material we adopt a value of $14 \%$. This represents a minimum value in available data and is regarded as an appropriate value for weld material. In the absence of data for the weld material, the same data is adopted for both parent and weld. The estimate of total lifetime, corresponding to crack initiation, is given by a linear summation of fatigue and creep damage i.e. the total number of cycles to failure $N_{0}^{*}$ is given by;

$$
\frac{1}{N_{0}^{*}}=\frac{1}{N_{f}}+\frac{1}{N_{c}}
$$

As the creep strain is small, its inclusion in the total strain range $\Delta \varepsilon_{t}$ has a negligible effect on fatigue damage.

Table 3 and 4 show typical results for $\Delta M=1.24 \Delta M_{s h}$ for the numbers of cycles to failure evaluated, again, on either side of the weld interface. The load level corresponds to a total strain range of $0.5 \%$ on the outer fibres of the parent material away from the weld, i.e. at a fairly severe state of loading. There are two notable features of these results. For increasing dwell periods, creep damage quickly dominates and, for a dwell period of $5 \mathrm{hrs}$, the number of cycles to failure, ignoring fatigue, is close to the predicted value. At the same time there is a movement of the critical location with increasing dwell time. In the absence of a dwell period, failure first occurs in the parent material where the maximum plastic strain range occurs. As the dwell period increases, 
the critical point moves to the weld material where the maximum stress occurs. For a $1 \mathrm{hr}$ dwell period, $N_{0}^{*}$ is near equal at the two locations, but for a $5 \mathrm{hr}$ dwell period, the critical position is in the weld. As the creep ductility of the weld material is likely to be less than in the parent material, this implies that failure in the weld with a creep dominated mode is the most likely failure mode.

In the following section, we develop a simple analytic description of the behaviour of key parameters in the parent material, remote from the range. This allows a normalisation of the behaviour adjacent to the weld interface as deviations from the remote behaviour, over a wide range of loads and dwell periods. This forms the basis for a semi-analytic solution to the life of the weld.

\section{Behaviour Remote from the Weld}

Consider a beam problem where a section of beam of thickness $\mathrm{h}$ and breadth $\mathrm{b}$ is subjected to a reversing bending moment of amplitude $\Delta M$.

Consider the Ramberg-Osgood relationship (1) and (2), repeated here for uniaxial or effective stress and strain,

$$
\Delta \varepsilon=\frac{\Delta \sigma}{E}+A(\Delta \sigma)^{\frac{1}{\beta}}
$$

There are two extreme solutions. Consider the case when the plastic strain amplitude is ignored. The maximum linear elastic stress amplitude is then given by;

$$
\Delta \sigma_{\max }^{e}=\frac{6}{b h^{2}} \Delta M, \Delta \varepsilon_{\max }^{e}=\frac{\Delta \sigma_{\max }^{e}}{E}
$$

The elastic shakedown limit $\Delta M_{s h}^{R}$ is given by a reverse plasticity limit when $\Delta \sigma=2 \sigma_{y}$, i.e.

$$
\Delta M_{s h}^{R}=\frac{b h^{2}}{3} \sigma_{y}
$$

Comparisons with the LMM solution gives that $\Delta M_{s h}=1.015 \Delta M_{s h}^{R}$, a $1.5 \%$ increase due to the elastic stress concentration at the weld interface.

Another extreme is given by the case when the elastic strain amplitude is negligible and the total strain range is given by the second term in equ. (12). In this case a simple analytic solution is possible, Ponter and Chen [9]. The solution is best normalised with respect to a reference plastic strain amplitude $\Delta \varepsilon_{0}^{p}$ corresponding to a stress reference stress amplitude $\Delta \sigma_{0}=2 \sigma_{y}$ where these quantities are related by $\Delta \varepsilon_{0}^{p}=A\left(\Delta \sigma_{0}\right)^{1 / \beta}$. In the following we will choose $\Delta \varepsilon_{0}^{p}=0.2 \%$ as this corresponds to the definition of $\sigma_{y}$ used previously. The analytic solution, Ponter and Chen [9], may now be expressed in the following reference stress form, in terms of a reference stress range $\Delta \sigma_{R}$ and corresponding reference strain range $\Delta \varepsilon_{R}^{p}$, 


$$
\Delta \sigma_{R}=0.6801 \frac{\Delta M}{\Delta M_{s h}} 2 \sigma_{y}, \Delta \varepsilon_{\max }^{p}=1.57 \Delta \varepsilon_{R}^{p}
$$

where

$$
\Delta \varepsilon_{R}^{p}=0.2 \%\left(\frac{\Delta \sigma_{R}}{\Delta \sigma_{0}}\right)^{\frac{1}{\beta}}=0.2 \%\left(0.6801 \frac{\Delta M}{\Delta M_{s h}}\right)^{\frac{1}{\beta}}
$$

For the linear elastic solution, corresponding to $\beta=1$, equ. (15) still applies and equ. (16a) is replaced by

$$
\Delta \varepsilon_{R}^{e}=\frac{\Delta \sigma_{R}}{E}
$$

This suggests that a good approximation to the total strain range, in the case when both elastic and plastic terms in equ. (11) are included, will be given by the combination of equ. (16a) and equ. (16b),

$$
\Delta \varepsilon_{\max }=1.57 \Delta \varepsilon_{R} \text { where } \Delta \varepsilon_{R}=\Delta \varepsilon_{R}^{e}+\Delta \varepsilon_{R}^{p}
$$

where the individual reference values are given by equ. (16a) and equ. (16b) corresponding to the same reference stress equ. (15). In Figure (5) we show a comparison between this analytic solution for the plastic strain range and computed values from the LMM solution for both the remote solution and the solutions at the weld interface for $0 \leq \Delta M / \Delta M_{s h} \leq 2$ and $\beta=0.2996$. In Figure (6) we show the variation of the plastic strain amplitude, normalised with respect to the remote amplitude. Hence we see that the analytic solution equs. (15), (16) and (17) compares well with computed values. At the parent weld interface the maximum strain concentration occurs close to $\Delta M / \Delta M_{s h}=1$ in the parent material. Hence a conservative estimate of the maximum strain amplitude adjacent to the weld $\Delta \varepsilon_{\max }^{W}$ is given by

$$
\Delta \varepsilon_{\max }^{W}=1.30 \Delta \varepsilon_{\max }, \quad \text { in the parent material }
$$

The factor 1.30 corresponds to the Fatigue Strength Reduction Factor (FSRF), usually extracted from feature tests conducted on welds. Here we have derived this value from known elastic and plastic material properties.

For the creep damage calculations we require estimates of the maximum stress, prior to relaxation, $\sigma_{\max }^{i c}=\Delta \sigma_{\max } / 2$, and values of the elastic follow-up factor Z. Again these can be estimated analytically for the plate remote from the weld. The following expression is derived by Ponter and Chen [9] for the relationship equ. (12), ignoring elastic strains,

$$
\Delta \sigma^{\max }=1.015\left(\frac{2+\beta}{3}\right) \Delta \sigma_{R}, \quad \Delta \sigma_{R}=\frac{\Delta M}{\Delta M_{s h}} 2 \sigma_{y}
$$


Figure (6) shows a comparison between this equation, with $\beta=1$ (linear elasticity) and $\beta=0.2996$ (plastic strains only) with the computed values. The $\beta=1$ case coincides with the computed solution for low loads, whereas the slope of the computed solution coincides with the case $\beta=0.2996$ for $\Delta M / \Delta M_{s h}>0.8$. The following solution provides a good approximation in the weld material, over the entire range of load;

$$
\left\{\begin{array}{l}
\sigma_{\max }^{i c}=1.015 \sigma_{y} \frac{\Delta M}{\Delta M_{s h}}, \quad \text { when } \frac{\Delta M}{\Delta M_{s h}} \leq \alpha \\
\sigma_{\max }^{i c}=1.015 \sigma_{y}\left(\frac{2+\beta}{3} \frac{\Delta M}{\Delta M_{s h}}+\alpha \frac{1-\beta}{3}\right), \quad \text { when } \frac{\Delta M}{\Delta M_{s h}} \geq \alpha
\end{array}\right.
$$

where $\alpha=0.45$. In Figure (8) the initial creep stress is normalised with respect to the remote value. The maximum stress concentration at the weld occurs in the weld material as expected, for a practical load range, and a simple upper bound is given by

$$
\sigma_{\max }^{i c W}=1.20 \sigma_{\max }^{i c}, \text { in the weld material }
$$

\section{Estimates of the Elastic Follow-up Factor Z}

The value of the elastic follow-up factor $\mathrm{Z}$ depends upon the non-linearity of the creep behaviour, i.e. the exponent $\mathrm{n}$, and the entire initial distribution of stress, governed by the elastic/plastic properties. Close analytic estimates are, in this case, more difficult to obtain. However a suitable method is given by Ponter and Chen [9] for the case when plastic strains dominate. This results in the following estimate;

$$
Z=\frac{\beta n+2}{\beta n-1}
$$

For low bending moments when elastic strains dominate, the corresponding $\mathrm{Z}$ value is given by $n=4.18$ and $\beta=1$, i.e $Z=1.94$. For high moments, when plastic strain dominate, $n=4.18$ and $\beta=0.2996$ then $Z=12.86$. Hence there is an expectation that $\mathrm{Z}$ will vary significantly with load level. The computed values are shown in Fig, (9), computed for a dwell time of $5 \mathrm{hrs}$, although the value is insensitive to dwell time. The values remote from the weld vary within this predicted range whereas the values at the weld interface exhibit a rather different mode of behaviour. For low loads $\mathrm{Z}$ values are relatively constant and only begin to increase significantly when $\Delta M / \Delta M_{s h}>1.2$. In our model we replace these computed values by the following analytic expressions,

Remote parent:

$$
Z=2.1204+0.04652 \frac{\Delta M}{\Delta M_{s h}}+1.22932\left(\frac{\Delta M}{\Delta M_{s h}}\right)^{2}
$$


Weld interface (weld):

$$
\begin{gathered}
\mathrm{Z}=2, \quad \frac{\Delta M}{\Delta M_{s h}}<1.2 \\
Z=-55.98168+140.11189 \frac{\Delta M}{\Delta M_{s h}}-113.20737\left(\frac{\Delta M}{\Delta M_{s h}}\right)^{2}+30.68281\left(\frac{\Delta M}{\Delta M_{s h}}\right)^{3} \\
\frac{\Delta M}{\Delta M_{s h}}>1.2
\end{gathered}
$$

Weld interface (parent):

$$
\begin{gathered}
\mathrm{Z}=3, \quad \frac{\Delta M}{\Delta M_{s h}}<1.2 \\
Z=-8.04497+27.52588 \frac{\Delta M}{\Delta M_{s h}}-24.75466\left(\frac{\Delta M}{\Delta M_{s h}}\right)^{2}+7.87641\left(\frac{\Delta M}{\Delta M_{s h}}\right)^{3} \\
\frac{\Delta M}{\Delta M_{s h}}>1.2
\end{gathered}
$$

With these expressions, it is now possible to evaluate the accumulated creep strain from the creep behaviour and initial stress, equ.(20). A comparison between the predictions of this model and the experimental data for the tests on cruciform specimens reported Bretherton et al [1], is shown in Fig. (10a). The axes are given by the number of cycles to failure and the plastic total strain range at the surface remote from the weld.

The comparison between the predicted number of cycles and the experimental data for $1 \mathrm{hr}$ and $5 \mathrm{hr}$ dwell periods is satisfactory, taking into account the small number of data points and the difficulties encountered in controlling the tests. The comparison for the zero dwell time tests is less satisfactory, the model being non-conservative. The strain range for the parent material uniaxial fatigue data and the tests differ by a factor, the Fatigue Strength Reduction Factor (FSRF) of approximately 1.65. The model predicts a lower value of $\mathrm{FSRF}=1.30$, equ. (17). This difference is important as FSRF=1.65 is currently in practical use; its evaluation was a primary purpose of the tests of Bretherton et al [1,2].

Hence the model provides a good correlation with experimental data except in the case when the dwell time is zero. As fatigue and creep damage appears to occur relatively independent at separate locations, a simple adaptation of the model may be achieved by changing the strain concentration factor in equ. (18) from the predicted value of FSRF=1.30 to the experimentally predicted 
value of 1.65. The results of the prediction of the model so adapted are shown in Fig. (10b). The behaviour within the creep dominated region is unchanged, but the transition between creep and fatigue damage is effected.

Insight into the behaviour of the model so adapted can be gained from Fig. (11). Contours of constant number of cycles to failure $N_{0}^{*}$ is shown for a wide range of dwell times and applied moments. Two regions are identified, fatigue-dominated and creepdominated. The contour that divided these regions corresponds to the condition that predictions of lifetimes for fatigue and creep alone are equal. It can be seem that the tests points for $1 \mathrm{hr}$ and $5 \mathrm{hr}$ dwell periods lie predominately in the creep dominated region. The zero dwell period tests are, of course entirely dominated by fatigue damage. For reference purposes a 30 year service line is included, i.e. assuming $N_{0}^{*} \Delta t=30$ years. The line is, of course, entirely within the creep-dominated region. For six month dwell periods $\left(N_{0}^{*}=60\right)$ then $\Delta M / \Delta M_{s h}>1$, i.e. the loading is well above the shakedown limit, local plastic strains are dominant, initial stresses are dominated by the prediction of the Ramberg-Osgood relationship (2), neglecting elastic strains and the damage is dominated by creep damage. These 30 year calculations are included for purposes of illustration, as extrapolation of the model well beyond the conditions of the test would require careful consideration of relevant material data.

\section{Discussion}

The calculations discussed in this paper demonstrate that it is possible to model the behaviour of a weld subjected to creep/fatigue interaction, using basic material data and the Linear Matching Method. The assumptions in the model are simple, the RambergOsgood relationship from plastic behaviour and simple Norton-Bailey times hardening for stress creep relaxation. Failure, understood as crack initiation, is modelled as a simple linear summation of fatigue and creep damage, creep damage being included as ductility exhaustion. The LMM solutions are then used to derive an analytic model, using suitable reference stress approximations to conditions remote from the weld. For the evaluation of the elastic follow-up factor Z, the behaviour is complex. For high temperature applications, damage is dominated by creep damage and this is sensitive to the value of $\mathrm{Z}$.

Comparisons between the prediction of the model and experimental data show that there is a satisfactory prediction of creep dominated failure and a less satisfactory prediction of fatigue failure. There are a number of possible reasons for this. Although elastic and plastic material data was available for the weld and parent materials, no such separate data was available for fatigue life. Fatigue failure was predicted to occur in the parent material at the weld/fatigue interface where the heat affected zone (HAZ) occurs. The HAZ may well have poorer fatigue properties than the parent material. This may be corrected, in a simple way by adjusting the Fatigue Strength Reduction Factor of 1.30 in equ. (18) to 1.65, thereby making use of the cruciform data. The effect of this change is shown in Fig. (10b) where, in comparison with Fig. (10a), it can be seen that the zero dwell time predictions become satisfactory and the creep dominated predictions remain satisfactory. 
The analysis in this paper paves the way for the development of models for the reduction of strength of structures due to the presence of welds that are consistent with material data variations, experimental data on welds and our mechanical understanding of the interaction of plasticity and creep.

\section{Conclusions}

The precise prediction of the life of a weld when subjected to reverse plasticity and creep damage remains a very difficult problem. A full understanding of behaviour requires, in principle, extensive failure and deformation data for the parent material and weld materials as well as the heat affected zone. This is rarely, if ever, available. The approach here involves a simplified analysis of the steady cyclic state, using the same material and structural assumptions that are used in the UK life assessment method R5. The purpose of the work is to investigate the extent to which such a simplified analysis is capable of providing insight into the interaction between material and mechanical aspects. By normalising the numerical solutions with respect to analytic reference stress solutions for the behaviour remote from the well, the behaviour of the weld may be understood in terms of strain and stress enhancement factors. The strain factor corresponds to the Fatigue Strength Reduction Factor (FSRF), currently in use in design, whereas the stress enhancement factor gives the initial stress state at which creep induced stress relaxation occurs. An estimate of the elastic follow-up factor then completes the analysis. An important result of the analysis is the observation that creep damage and fatigue damage are dominant at differing locations on either side of the parent-weld material interface. This provides a pathway towards models of weld behaviour that include a reasonable complex understanding of failure but retain sufficient simplicity for direct use in design. The comparison between the simplified model and the experimental data on welds, discussed here, indicates that this approach is capable of predicting weld lifetimes reasonable accurately.

\section{Acknowledgements}

The work of this paper was made possible by a grant in aid of research to the University of Leicester by British Energy Ltd, for which the authors express their gratitude. Thanks are due to Dr R. A. Ainsworth, Manus O’Donnell, David Tipping and David Dean for technical assistance and for the provision of material data and test results.

\section{References}

1. Bretherton I, Knowles G, Hayes J P, Bate S K and Austin C J, 2004, "PC/AGR/5087: Final report on the fatigue and creepfatigue behaviour of welded cruciform joints", Report RJCB/RD01186/R01, British Energy, Barnwood, Gloucester, UK, January 2004.

2. I Bretherton and P J Budden, 1999, “Assessment of creep-fatigue endurance of large cruciform weldments”, Trans. SMiRT 15, Seoul, IV, pp185-192. 
3. Ponter A. R. S. and Engelhardt M., 2000, "Shakedown Limits for a General Yield Condition: Implementation and Examples for a Von Mises Yield Condition”, European Journal of Mechanics, A/Solids, 19, pp423-446.

4. Chen H. F and Ponter A. R. S.,2001, “A method for the evaluation of a ratchet limit and the amplitude of plastic strain for bodies subjected to cyclic loading”, European Journal of Mechanics A/Solids, 20, pp555-572.

5. Chen H. F. and Ponter A. R. S., 2002, "The 3-D shakedown and limit analysis using the linear matching method", International Journal of Pressure Vessel and Piping, 78, pp443-451.

6. Chen H. F. and Ponter A.R.S., 2003, "Application of the Linear Matching Method to the Integrity Assessment for the High Temperature Response of Structures”, ASME Pressure Vessels and Piping Division (Publication) PVP, 458, 2003, pp 3-12

7. Chen H. and Ponter A. R. S., 2004, "Integrity assessment for a tubeplate using the linear matching method", International Journal of Pressure Vessel Technology, 81, pp327-336.

8. Chen H. and Ponter A. R. S., 2004, "A simplified creep-reverse plasticity solution method for bodies subjected to cyclic loading”, European Journal of Mechanics, A/Solids, 81, pp651-577.

9. Ainsworth R.A. (editor), 2003, "R5: Assessment Procedure for the High Temperature Response of Structures, Issue 3", British Energy Generation Ltd, Barnwood, Gloucestershire, UK.

10. Ponter A. R. S. and Chen H., "The Development of a Failure Model for Welds under Variable Load at High Temperature", Department of Engineering, University of Leicester, Internal Report, January 2006. 


\begin{tabular}{|c|c|c|c|c|c|}
\hline & & $\mathrm{E}(\mathrm{MPa})$ & $\mathrm{A}(\mathrm{MPa})$ & $\beta$ & $\sigma_{y}(\mathrm{MPa})$ \\
\hline Parent Plate & 1 & 160000 & 289.20 & 0.13800 & \\
& 100 & 160000 & 3591.20 & 0.42792 & \\
& Saturated & 160000 & 1741.96 & 0.29960 & 219.9 \\
\hline Weld & 1 & 122000 & 658.82 & 0.13384 & \\
(MMA) & 100 & 122000 & 585.19 & 0.09686 & \multirow{2}{*}{286.9} \\
\hline Heat & Saturated & 122000 & 578.99 & 0.10162 & \\
Affected & 1 & 154000 & 1577.05 & 0.27977 & \\
Zone & 100 & 154000 & 1803.88 & 0.27451 & \\
& Saturated & 154000 & 1632.31 & 0.25304 & \\
\hline
\end{tabular}

Table 1 Material parameters for elastic and plastic properties for $316 \mathrm{~N}(\mathrm{~L})$ at $550^{\circ} \mathrm{C}$.

\begin{tabular}{|c|c|c|}
\hline Location & Z- Dwell time $1 \mathrm{hr}$ & Z- Dwell time $5 \mathrm{hrs}$ \\
\hline Weld material & 3.01 & 3.04 \\
\hline Parent material & 2.15 & 2.19 \\
\hline
\end{tabular}

Table 2. Values of the elastic follow-up factor $\mathrm{Z}$ on either side of the weld/ parent material interface at the surface for $\Delta M=1.24 \Delta M_{s h}$.

\begin{tabular}{|c|c|c|c|}
\hline $\begin{array}{c}\text { Hold period } \\
\text { (Hours) }\end{array}$ & $\begin{array}{l}\text { Cycles to failure, } \\
\text { Fatigue, } N_{\mathrm{f}}\end{array}$ & $\begin{array}{l}\text { Cycles to failure } \\
\text { Creep, } N_{c}=1 / D_{c}\end{array}$ & $\begin{array}{c}\text { Estimation of } \\
\text { lifetime, } N_{0}^{*}\end{array}$ \\
\hline 0 & 26875 & $\infty$ & 26875 \\
\hline 1 & 26066 & 3037 & 2719 \\
\hline 5 & 25294 & 1573 & 1481 \\
\hline
\end{tabular}

Table 3. Life predictions evaluated at the weld toe (weld) for the weld specimen subjected to a cyclic bending moment for $\Delta M=1.24 \Delta M_{s h}$ producing a total effective strain range $0.5 \%$ at the remote outer fibre of the parent material

\begin{tabular}{|c|c|c|c|}
\hline $\begin{array}{c}\text { Hold period } \\
\text { (Hours) }\end{array}$ & $\begin{array}{l}\text { Cycles to failure, } \\
\text { Fatigue, } \mathrm{N}_{\mathrm{f}}\end{array}$ & $\begin{array}{c}\text { Cycles to failure } \\
\text { Creep, } N_{c}=1 / D_{c}\end{array}$ & $\begin{array}{c}\text { Estimation of lifetime, } \\
N_{0}^{*}\end{array}$ \\
\hline 0 & 10358 & $\infty$ & 10358 \\
\hline 1 & 10173 & 3675 & 2699 \\
\hline 5 & 9994 & 1915 & 1607 \\
\hline
\end{tabular}

Table 4. Summary of life predictions evaluated at the weld toe (parent) for the weld specimen subjected to a cyclic bending moment of $\Delta M=1.24 \Delta M_{s h}$ producing a total effective strain range $0.5 \%$ at the remote outer fibre of the parent material 


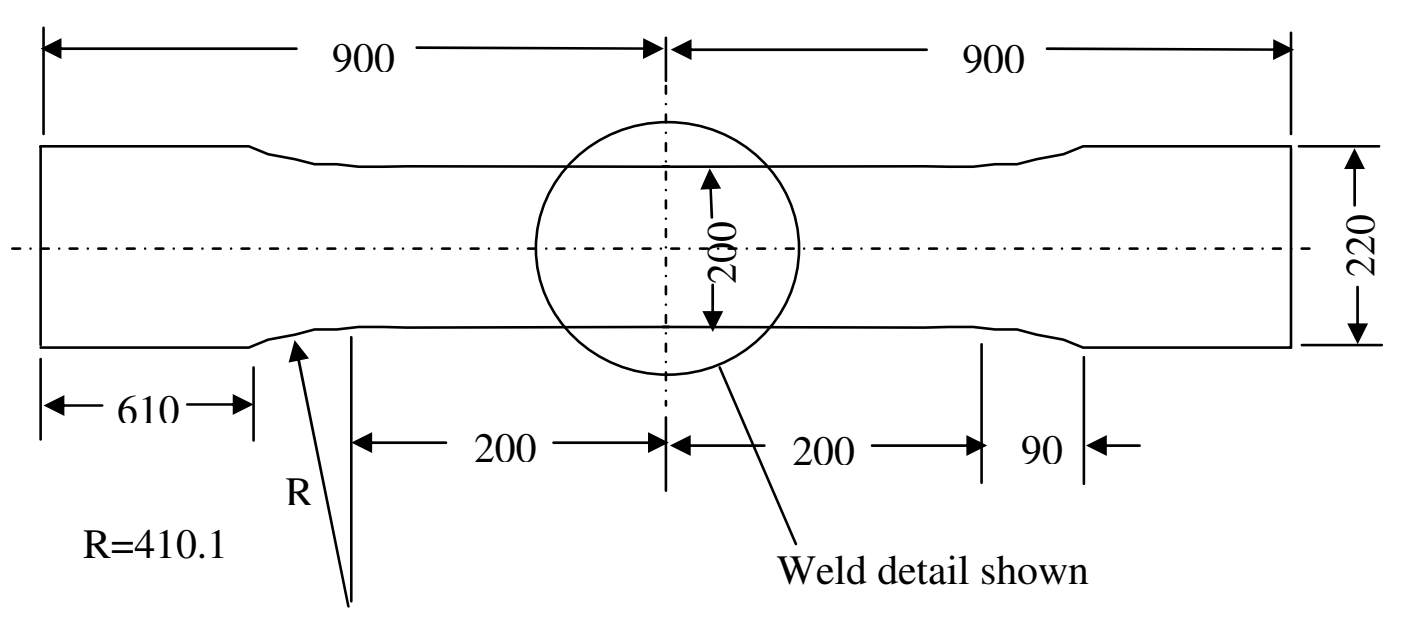

(a)

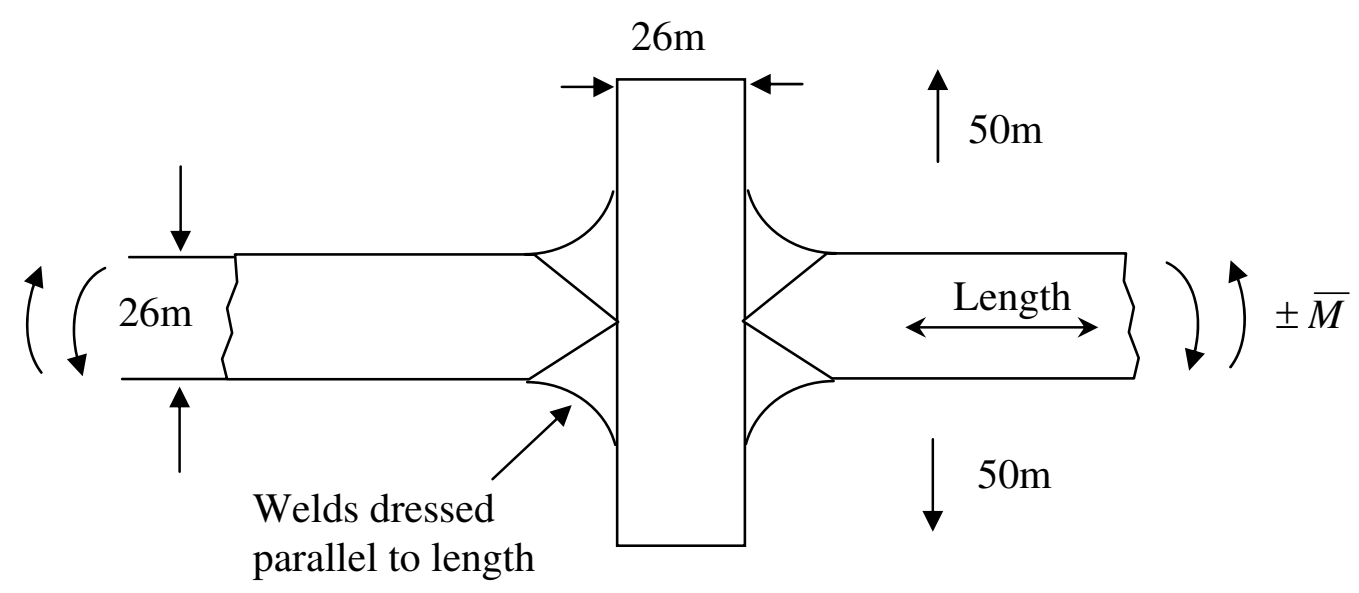

(b)

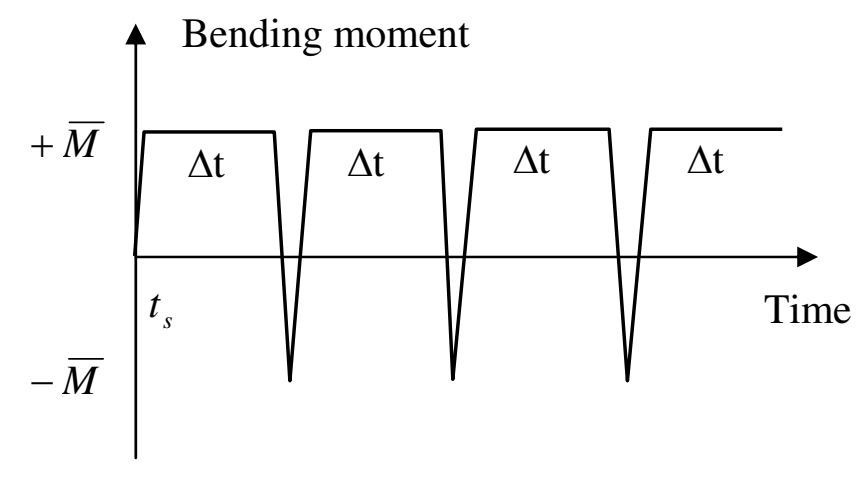

(c)

Figure 1. Dimensions of the cruciform weld specimens, (a) and (b), and schematic of the assumed loading history, (c). 


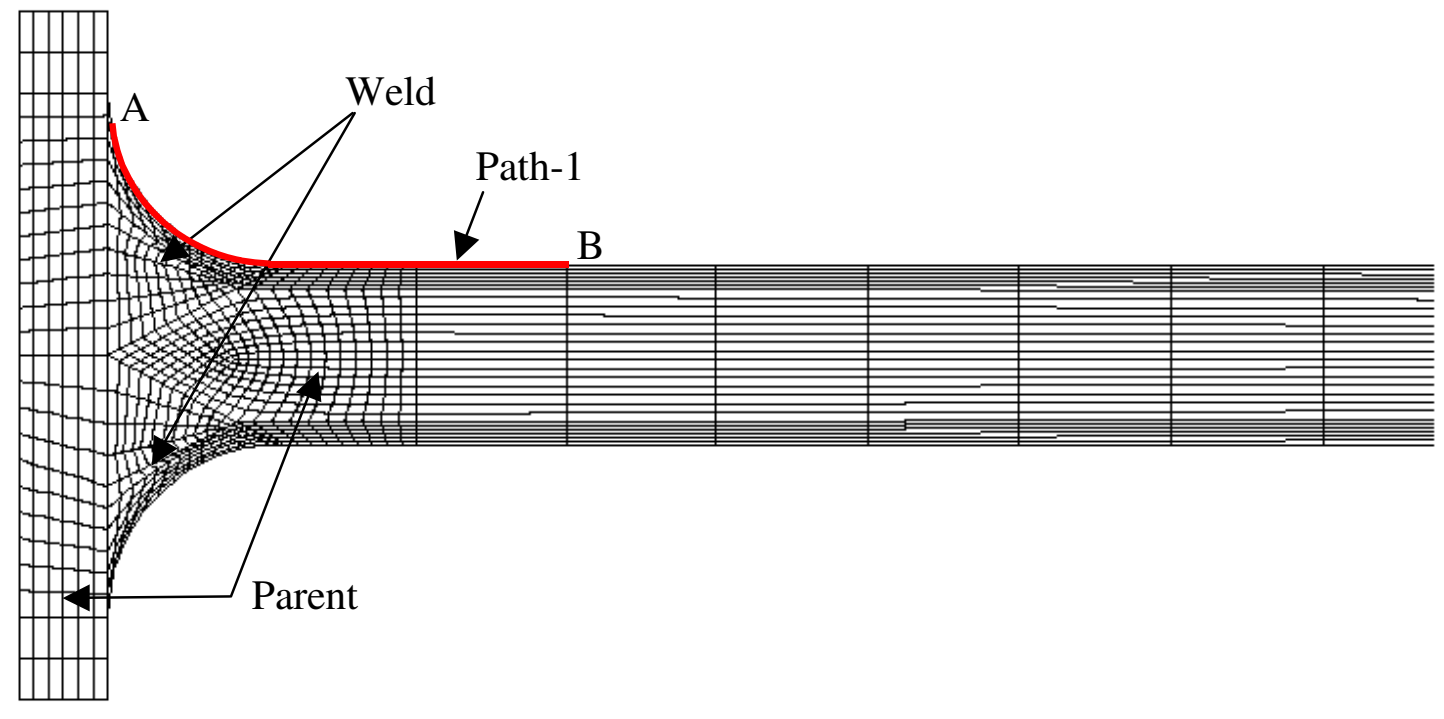

(a)

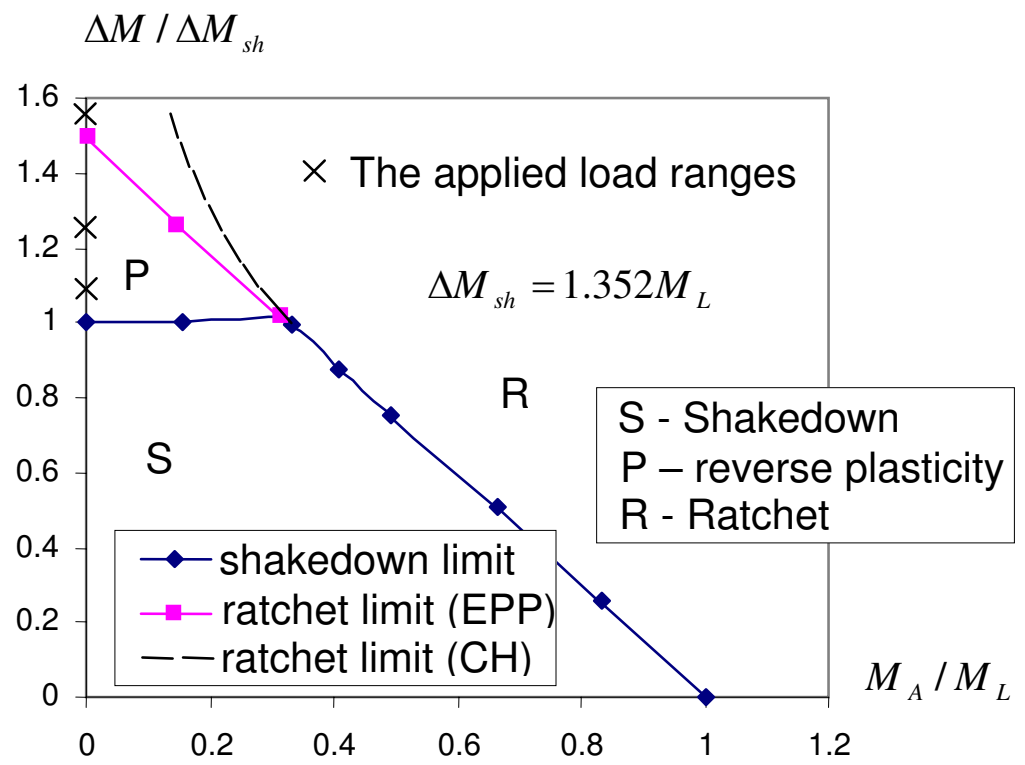

(b)

Figure 2. (a) Finite element mesh and (b) the shakedown limit interaction curve for weld specimen subjected to cyclic reverse bending moment $\Delta M$ and constant bending moment $M_{A}$ 


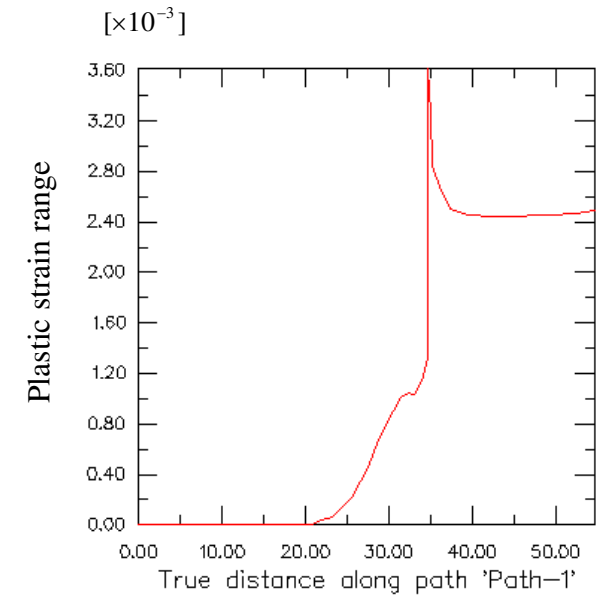

(a)

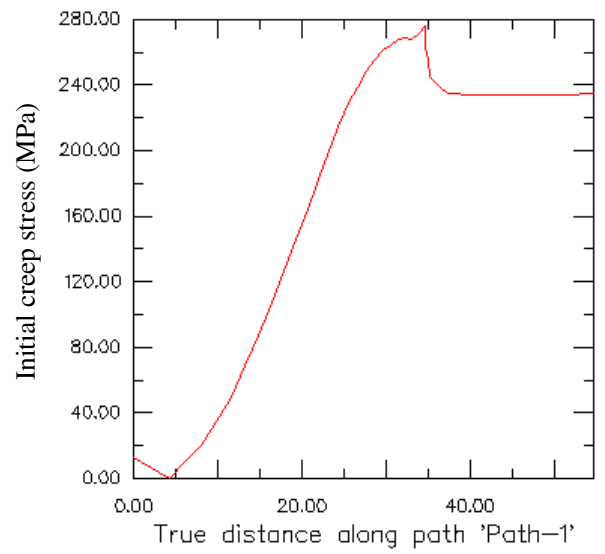

(b)

Figure 3. The effective plastic strain range with saturated cycle data with no hold period, (a), and maximum effective stress, (b), for saturated steady state cycle $\Delta M=12.466 \mathrm{kNm}=1.24 \Delta M_{s h}$. The distribution corresponds to the surface values along the path $\mathrm{AB}$ in Figure 2(a).

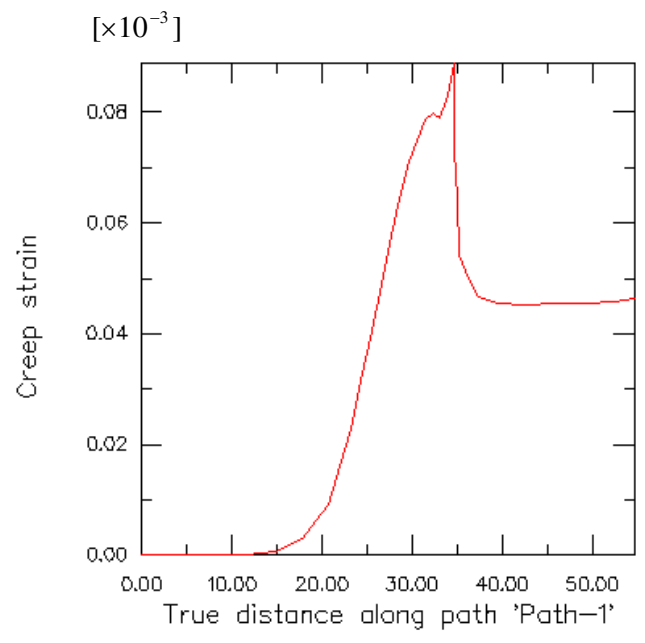

(a)

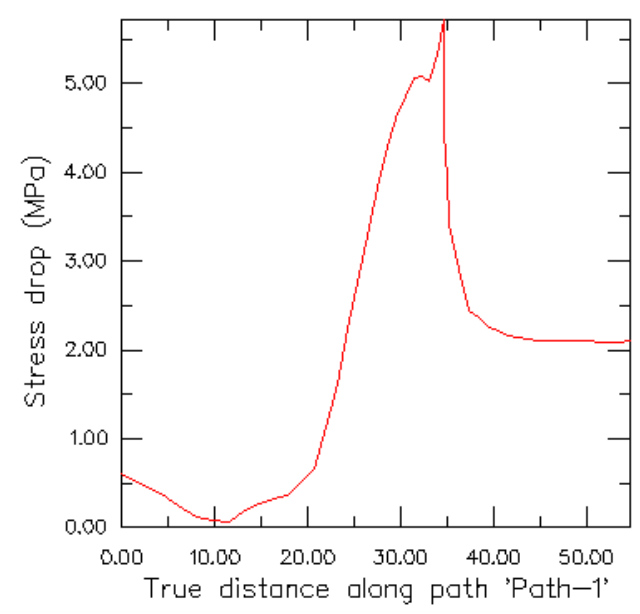

(b)

Figure 4. The effective creep strain after 5 hours hold period, (a), and the effective creep stress drop after 5 hours hold period, (b), $\Delta M=12.466 \mathrm{kNm}=1.24 \Delta M_{s h}$. 


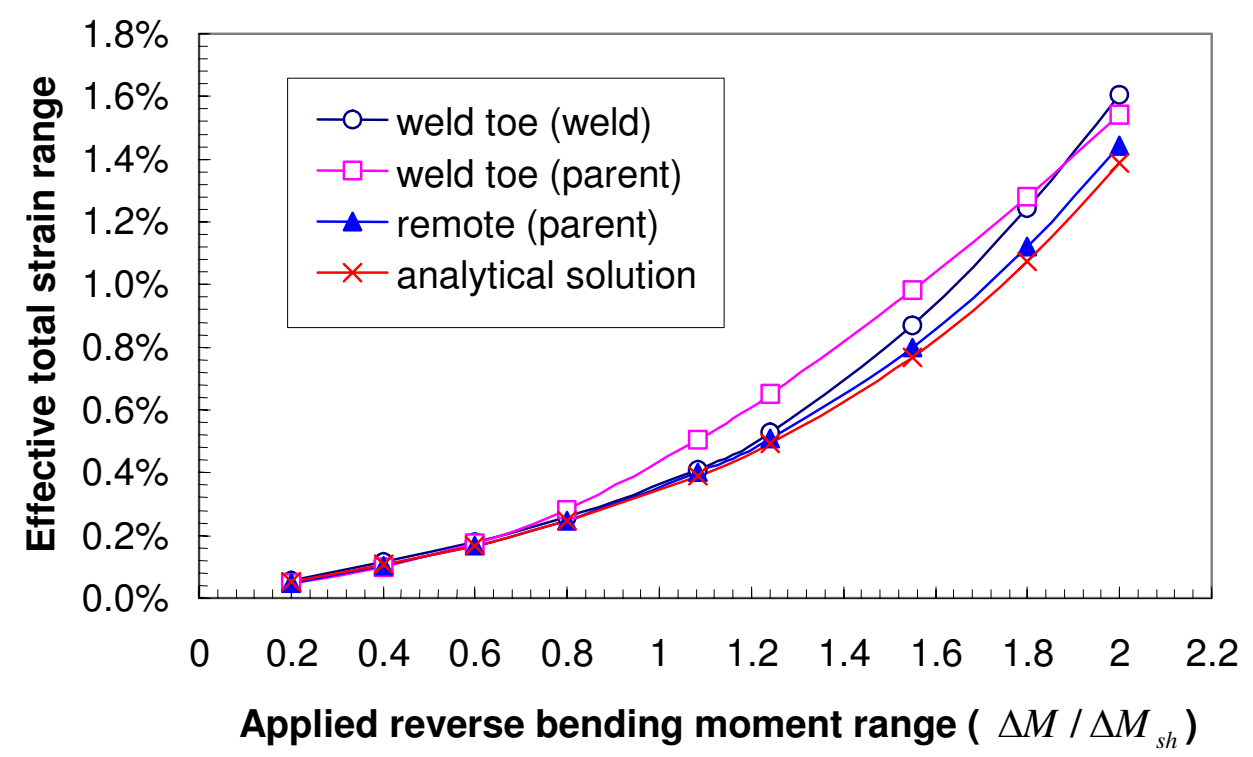

Figure 5. Computed variation of the total effective strain range at critical locations and comparison with the analytic solution, equs. (15), (16) and (17) remote from the weld.

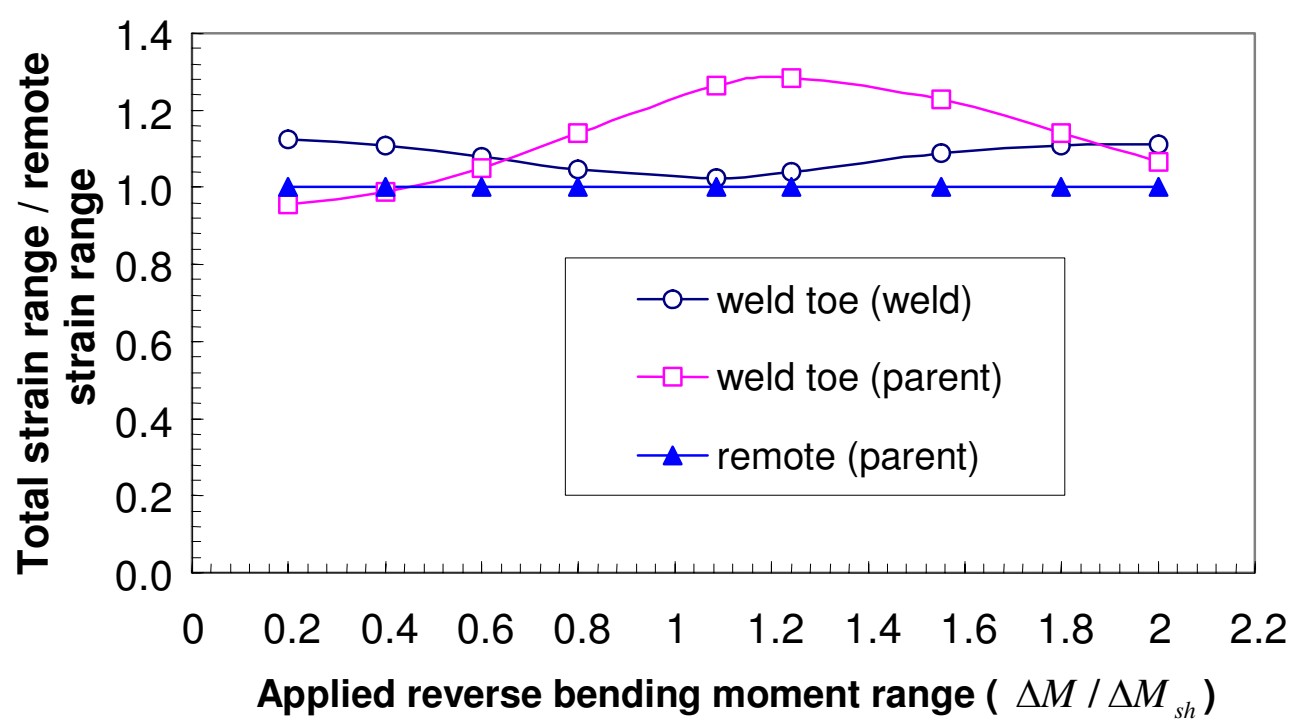

Figure 6. Computed variation of the total strain range at critical locations normalised with respect to the solution remote from the weld. 


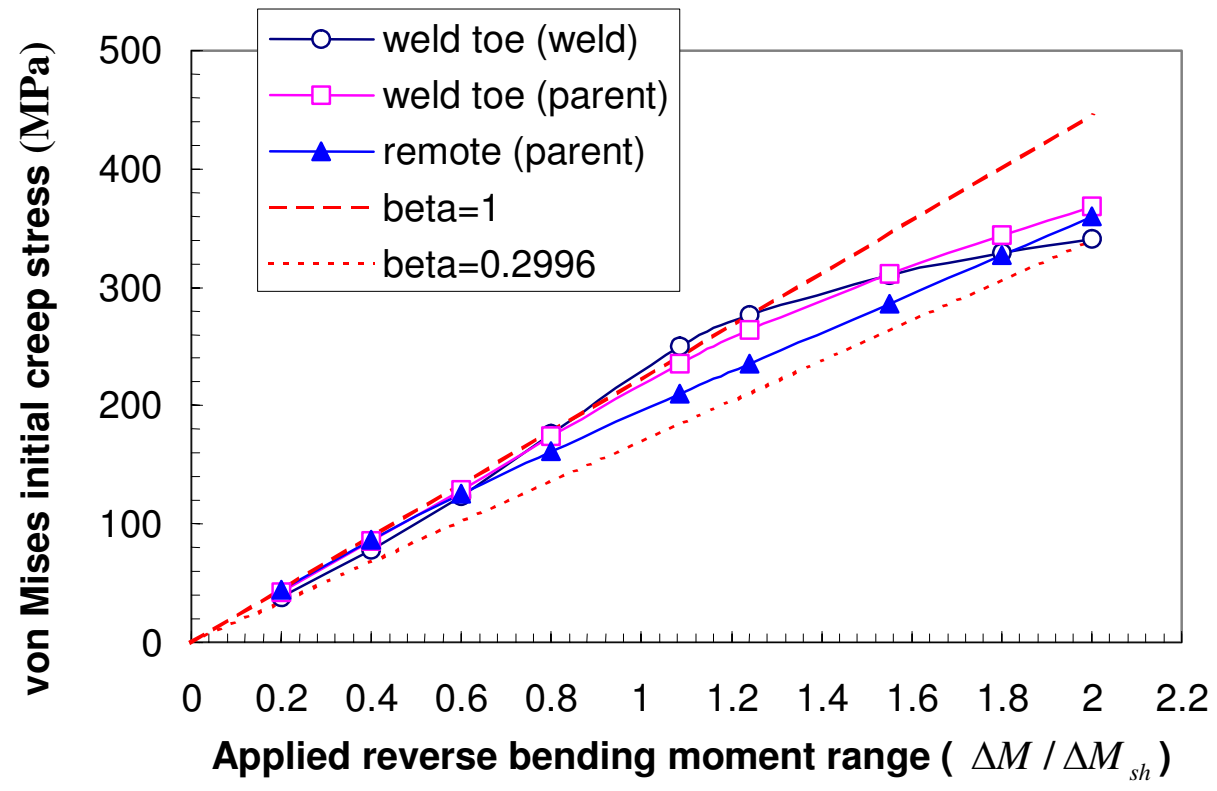

Figure 7. The variation of the maximum stress from the plasticity calculation, the initial creep stress, at critical locations and comparison with the analytic solution, equ. (19).

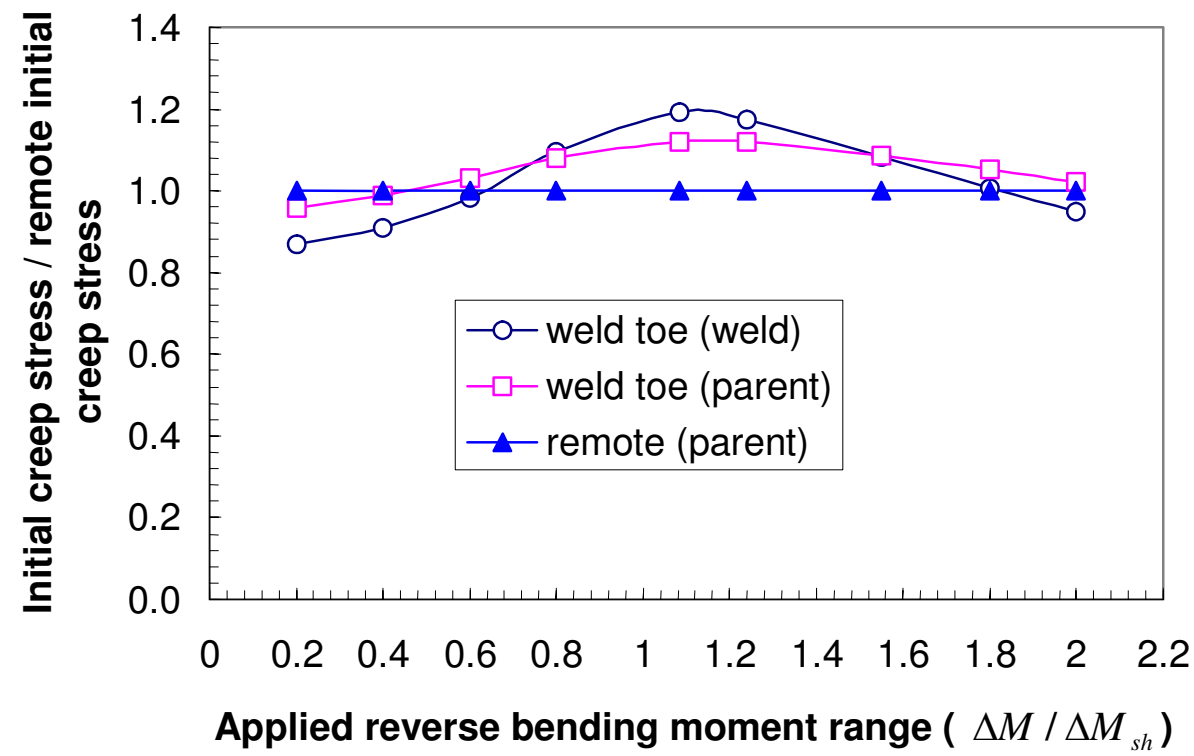

Figure 8. The variation of the maximum stress from the plasticity, the initial creep stress, calculation at critical locations and normalised with respect to the remote solution, equ. (20). 


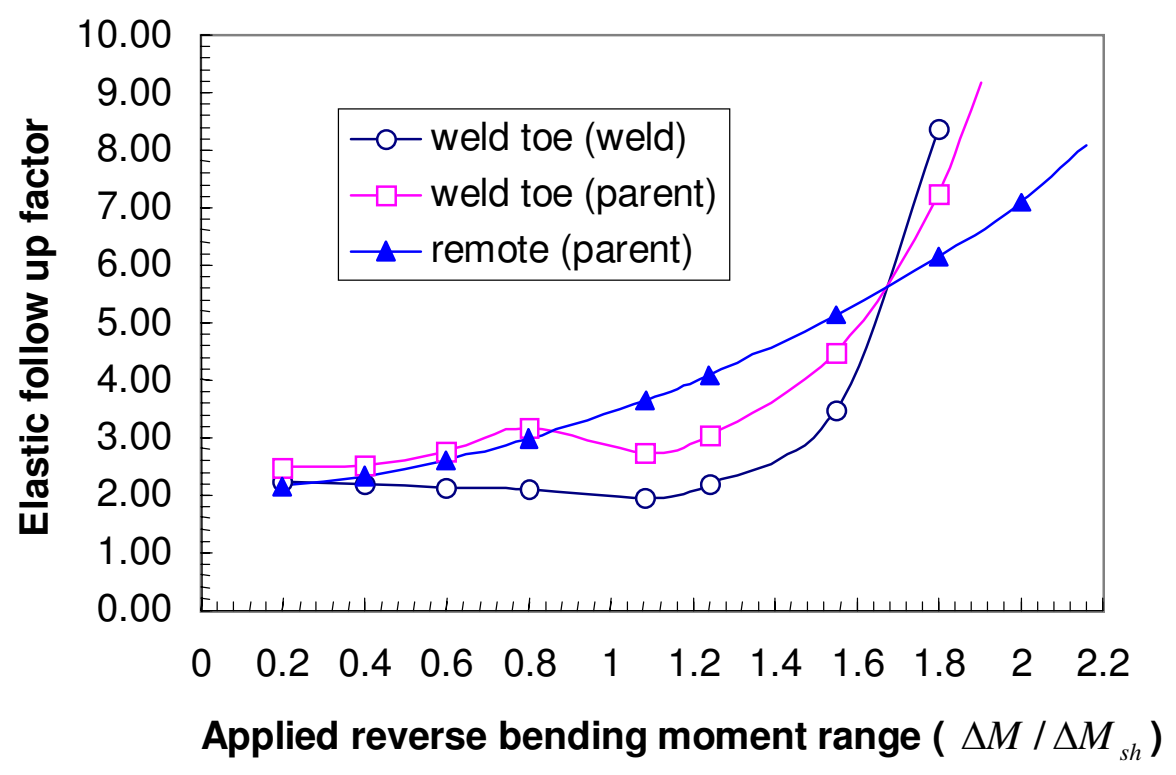

Figure 9. Variation of the elastic follow-up factor $\mathrm{Z}$ with load at critical locations. 


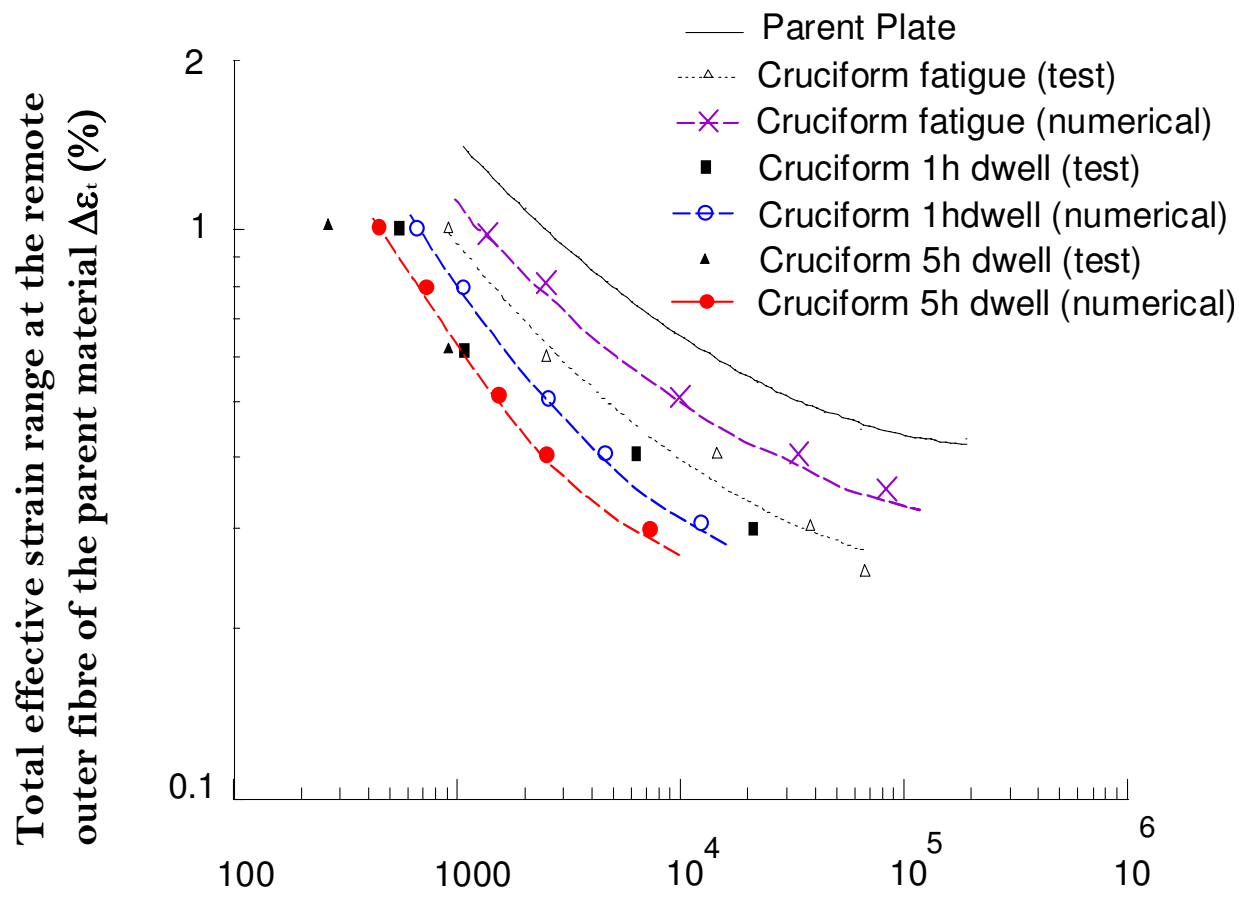

Total lifetime $\mathbf{N}$ cycles

(a)

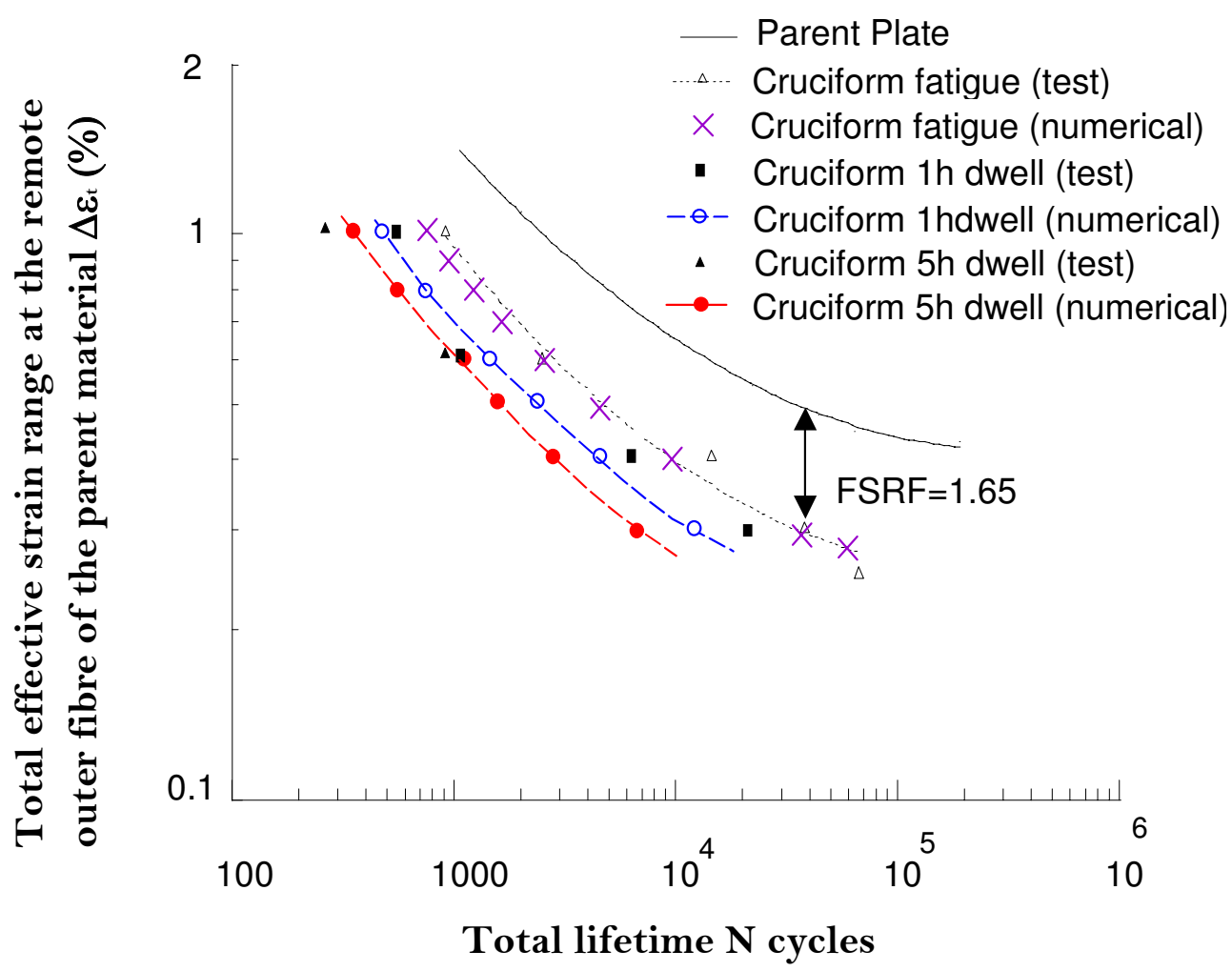

(b)

Figure 10. Comparison between the predictions of the model and experimental failure values, Bretherton et al [1], for tests conducted at $550^{\circ} \mathrm{C}$ (a) direct comparison with the model, (b) the model adapted so that $\mathrm{FSRF}=1.65$ 


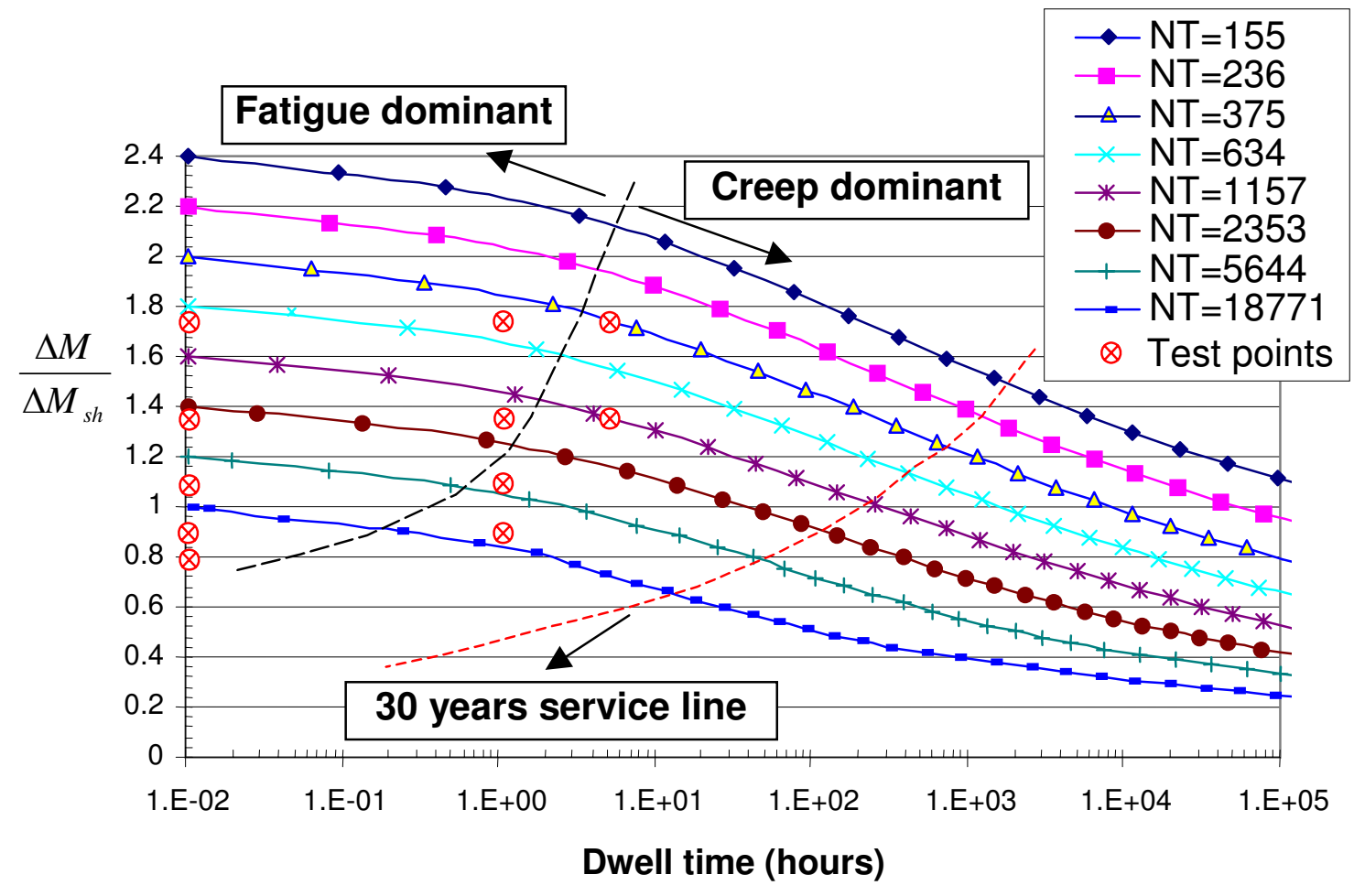

Figure 11. Contours of constant cycles to failure $N_{0}^{*}$, based upon the analytic model. (Assuming $\mathrm{FSRF}=1.65$ ) 


\section{Figure Captions}

Figure 1. Dimensions of the cruciform weld specimens, (a) and (b), and schematic of the assumed loading history, (c).

Figure 2. (a) Finite element mesh and (b) the shakedown limit interaction curve for weld specimen subjected to cyclic reverse bending moment $\Delta M$ and constant bending moment $M_{A}$

Figure 3. The effective plastic strain range with saturated cycle data with no hold period, (a), and maximum effective stress, (b), for saturated steady state cycle $\Delta M=12.466 \mathrm{kNm}=1.24 \Delta M_{s h}$. The distribution corresponds to the surface values along the path $\mathrm{AB}$ in Fig. 2(a).

Figure 4. The effective creep strain after 5 hours hold period, (a), and the effective creep stress drop after 5 hours hold period, (b), $\Delta M=12.466 \mathrm{kNm}=1.24 \Delta M_{s h}$.

Figure 5. Computed variation of the total effective strain range at critical locations and comparison with the analytic solution, equs. (15), (16) and (17) remote from the weld.

Figure 6. Computed variation of the total strain range at critical locations normalised with respect to the solution remote from the weld.

Figure 7. The variation of the maximum stress from the plasticity calculation, the initial creep stress, at critical locations and comparison with the analytic solution, equ. (19).

Figure 8. The variation of the maximum stress from the plasticity, the initial creep stress, calculation at critical locations and normalised with respect to the remote solution, equ. (20).

Figure 9. Variation of the elastic follow-up factor $\mathrm{Z}$ with load at critical locations.

Figure 10. Comparison between the predictions of the model and experimental failure values, Bretherton et al [1], for tests conducted at $550^{\circ} \mathrm{C}$ (a) direct comparison with the model, (b) the model adapted so that $\mathrm{FSRF}=1.65$.

Figure 11. Contours of constant cycles to failure $N_{0}^{*}$, based upon the analytic model. (Assuming $\mathrm{FSRF}=1.65)$ 